\title{
Common Fixed Points of Multistep Noor Iterations with Errors for a Finite Family of Generalized Asymptotically Quasi-Nonexpansive Mappings
}

\author{
S. Imnang and S. Suantai \\ Department of Mathematics, Faculty of Science, Chiang Mai University, Chiang Mai 50200, Thailand \\ Correspondence should be addressed to S. Suantai, scmti005@chiangmai.ac.th
}

Received 3 July 2009; Accepted 5 September 2009

Recommended by Simeon Reich

We introduce a general iteration scheme for a finite family of generalized asymptotically quasinonexpansive mappings in Banach spaces. The new iterative scheme includes the multistep Noor iterations with errors, modified Mann and Ishikawa iterations, three-step iterative scheme of $\mathrm{Xu}$ and Noor, and Khan and Takahashi scheme as special cases. Our results generalize and improve the recent ones announced by Khan et al. (2008), H. Fukhar-ud-din and S. H. Khan (2007), J. U. Jeong and S. H. Kim (2006), and many others.

Copyright (C) 2009 S. Imnang and S. Suantai. This is an open access article distributed under the Creative Commons Attribution License, which permits unrestricted use, distribution, and reproduction in any medium, provided the original work is properly cited.

\section{Introduction}

Let $C$ be a subset of real Banach space $X$. Let $T$ be a self-mapping of $C$ and let $F(T)$ denote the fixed points set of $T$, that is, $F(T):=\{x \in C: T x=x\}$. Recall that a mapping $T$ is said to be asymptotically nonexpansive on $C$ if there exists a sequence $\left\{b_{n}\right\}$ in $[0, \infty)$ with $\lim _{n \rightarrow \infty} b_{n}=0$ such that for each $x, y \in C$,

$$
\left\|T^{n} x-T^{n} y\right\| \leq\left(1+b_{n}\right)\|x-y\|, \quad \forall n \geq 1 .
$$

If $b_{n}=0$ for all $n \geq 1$, then $T$ is known as a nonexpansive mapping. $T$ is called generalized asymptotically quasi-nonexpansive [1] if there exist sequences $\left\{b_{n}\right\},\left\{c_{n}\right\}$ in $[0, \infty)$ with $\lim _{n \rightarrow \infty} b_{n}=0=\lim _{n \rightarrow \infty} c_{n}$ such that

$$
\left\|T^{n} x-p\right\| \leq\left(1+b_{n}\right)\|x-p\|+c_{n}, \quad \forall n \geq 1,
$$


for all $x \in C$ and all $p \in F(T)$. If $c_{n}=0$ for all $n \geq 1$, then $T$ is known as an asymptotically quasi-nonexpansive mapping. $T$ is called asymptotically nonexpansive mapping in the intermediate sense [2] provided that $T$ is uniformly continuous and

$$
\limsup _{n \rightarrow \infty} \sup _{x, y \in C}\left(\left\|T^{n} x-T^{n} y\right\|-\|x-y\|\right) \leq 0
$$

$T$ is said to be $(L-\gamma)$ uniform Lipschitz [3] if there are constants $L>0$ and $\gamma>0$ such that

$$
\left\|T^{n} x-T^{n} y\right\| \leq L\|x-y\|^{\gamma}, \quad \forall n \geq 1,
$$

for all $x, y \in C$. A mapping $T$ is called semicompact if any bounded sequence $\left\{x_{n}\right\}$ in $C$ with $\lim _{n \rightarrow \infty}\left\|x_{n}-T x_{n}\right\|=0$, there exists a subsequence $\left\{x_{n_{i}}\right\}$ of $\left\{x_{n}\right\}$ such that $\left\{x_{n_{i}}\right\}$ converges strongly to some $x^{*}$ in $C$.

Remark 1.1. Let $T$ be asymptotically nonexpansive mapping in the intermediate sense. Put $G_{n}=\sup _{x, y \in C}\left(\left\|T^{n} x-T^{n} y\right\|-\|x-y\|\right) \vee 0, \forall n \geq 1$.

If $F(T) \neq \varnothing$, we obtain that $\left\|T^{n} x-p\right\| \leq\|x-p\|+G_{n}$ for all $x \in C$ and all $p \in F(T)$. Since $\lim _{n \rightarrow \infty} G_{n}=0$, therefore $T$ is a generalized asymptotically quasi-nonexpansive mapping.

Recall that a mapping $T: C \rightarrow C$ with $F(T) \neq \varnothing$ is said to satisfy condition (I) [4] if there is a nondecreasing function $f:[0, \infty) \rightarrow[0, \infty)$ with $f(0)=0$ and $f(t)>0$ for all $t \in(0, \infty)$ such that $\|x-T x\| \geq f(d(x, F(T)))$ for all $x \in C$, where $d(x, F(T))=\inf \{\|x-p\|$ : $p \in F(T)\}$.

Fixed-point iteration processes for asymptotically quasi-nonexpansive mapping in Banach spaces including Mann and Ishikawa iterations processes have been studied extensively by many authors; see [3,5-11]. Many of them are used widely to study the approximate solutions of the certain problems. In 1974, Senter and Dotson [4] studied the convergence of the Mann iteration scheme defined by $x_{1} \in C$,

$$
x_{n+1}=\alpha_{n} T x_{n}+\left(1-\alpha_{n}\right)_{x_{n}}, \quad \forall n \geq 1,
$$

in a uniformly convex Banach space, where $\left\{\alpha_{n}\right\}$ is a sequence satisfying $0<a \leq \alpha_{n} \leq b<$ 1 for all $n \geq 1$ and $T$ is a nonexpansive (or a quasi-nonexpansive) mapping. They established a relation between condition (I) and demicompactness.

Recall that a mapping $T: C \rightarrow C$ is demicompact if for every bounded sequence $\left\{x_{n}\right\}$ in $C$ such that $\left\{x_{n}-T x_{n}\right\}$ converges, there exists a subsequence say $\left\{x_{n_{j}}\right\}$ of $\left\{x_{n}\right\}$ that converges strongly to some $y$ in $C$. Every compact and semicompact mapping is demicompact. They actually showed that condition (I) is weaker than demicompactness for a nonexpansive mapping defined on bounded set.

$\mathrm{Xu}$ and Noor [12], in 2002, introduced a three-step iterative scheme as follows:

$$
\begin{aligned}
z_{n} & =a_{n} T^{n} x_{n}+\left(1-a_{n}\right)_{x_{n}} \\
y_{n} & =b_{n} T^{n} z_{n}+\left(1-b_{n}\right)_{x_{n}}, \\
x_{n+1} & =\alpha_{n} T^{n} y_{n}+\left(1-\alpha_{n}\right)_{x_{n}}, \quad n \geq 1,
\end{aligned}
$$


where $\left\{a_{n}\right\},\left\{b_{n}\right\},\left\{\alpha_{n}\right\}$ are appropriate sequences in $[0,1]$. The theory of three-step iterative scheme is very rich, and this scheme, in the context of one or more mappings, has been extensively studied (e.g., see Khan et al. [6], Plubtieng and Wangkeeree [7], Fukhar-ud-din and Khan [5], Petrot [13], and Suantai [14]). It has been shown in [15] that three-step method performs better than two-step and one-step methods for solving variational inequalities.

In 2001, Khan and Takahashi [16] have approximated common fixed points of two asymptotically nonexpansive mappings by the modified Ishikawa iteration. Jeong and Kim [17] have approximated common fixed points of two asymptotically nonexpansive mappings. Plubtieng et al. [18], in 2006, modified Noor iterations with errors and have approximated common fixed points of three asymptotically nonexpansive mappings. Shahzad and Udomene [10] established convergence theorems for the modified Ishikawa iteration process of to asymptotically quasi-nonexpansive mappings to a common fixed point of the mappings. Plubtieng and Wangkeeree [7], in 2006, established strong convergence theorems of the modified multistep Noor iterations with errors for an asymptotically quasinonexpansive mapping and asymptotically nonexpansive mapping in the intermediate sense.

Very recently, Khan et al. [6], in 2008, established convergence theorems for the modified multistep Noor iterations process of finite family of asymptotically quasinonexpansive mappings to a common fixed point of the mappings. For rerated results with errors terms, we refer to $[5-7,17-21]$. Inspired and motivated by these facts, we introduce a new iteration process for a finite family of $\left\{T_{i}: i=1,2, \ldots, k\right\}$ of generalized asymptotically quasi-nonexpansive mappings as follows.

Let $T_{i}: C \rightarrow C(i=1,2, \ldots, k)$ be mappings and $F:=\bigcap_{i=1}^{k} F\left(T_{i}\right)$. For a given $x_{1} \in C$, and a fixed $k \in \mathbb{N}$ ( $\mathbb{N}$ denote the set of all positive integers), compute the iterative sequences $\left\{x_{n}\right\}$ and $\left\{y_{i n}\right\}$ by

$$
\begin{aligned}
x_{n+1}=y_{k n} & =\alpha_{k n} T_{k}^{n} y_{(k-1)_{n}}+\beta_{k n} x_{n}+\gamma_{k n} u_{k n}, \\
y_{(k-1) n} & =\alpha_{(k-1) n} T_{k-1}^{n} y_{(k-2) n}+\beta_{(k-1) n} x_{n}+\gamma_{(k-1) n} u_{(k-1) n}, \\
& \vdots \\
y_{3 n} & =\alpha_{3 n} T_{3}^{n} y_{2 n}+\beta_{3 n} x_{n}+\gamma_{3 n} u_{3 n}, \\
y_{2 n} & =\alpha_{2 n} T_{2}^{n} y_{1 n}+\beta_{2 n} x_{n}+\gamma_{2 n} u_{2 n}, \\
y_{1 n} & =\alpha_{1 n} T_{1}^{n} y_{0 n}+\beta_{1 n} x_{n}+\gamma_{1 n} u_{1 n},
\end{aligned}
$$

where $y_{0 n}=x_{n}$ and $\left\{u_{1 n}\right\},\left\{u_{2 n}\right\}, \ldots,\left\{u_{k n}\right\}$ are bounded sequences in $C$ with $\left\{\alpha_{i n}\right\},\left\{\beta_{i n}\right\}$, and $\left\{\gamma_{i n}\right\}$ are appropriate real sequences in $[0,1]$ such that $\alpha_{i n}+\beta_{i n}+\gamma_{\text {in }}=1$ for all $i=1,2, \ldots, k$ and all $n$. Our iteration includes and extends the Mann iteration (1.5), three-step iteration by $\mathrm{Xu}$ and Noor (1.6), the multistep Noor iterations with errors by Plubtieng and Wangkeeree [7], and the iteration defined by Khan et al. [6] simultaneously.

The purpose of this paper is to establish several strong convergence theorems of the iterative scheme (1.7) for a finite family of generalized asymptotically quasi-nonexpansive mappings when one mapping $T_{i}$ satisfies a condition which is weaker than demicompactness and we also weak convergence theorem for a finite family of generalized asymptotically quasi-nonexpansive mappings in a uniformly convex Banach space satisfying Opial's property. Our results generalize and improve the corresponding ones announced by Khan et al. [6], Fukhar-ud-din and Khan [5], and many others. 


\section{Preliminaries}

In the sequel, the following lemmas are needed to prove our main results.

A mapping $T$ with domain $D(T)$ and range $R(T)$ in $\mathrm{X}$ is said to be demiclosed at 0 if whenever $\left\{x_{n}\right\}$ is a sequence in $D(T)$ such that $\left\{x_{n}\right\}$ converges weakly to $x \in D(T)$ and $\left\{T x_{n}\right\}$ converging strongly to 0 , we have $T x=0$.

A Banach space $X$ is said to satisfy Opial's property if for each $x$ in $X$ and each sequence $\left\{x_{n}\right\}$ weakly convergent to $x$, the following condition holds for $x \neq y$ :

$$
\liminf _{n \rightarrow \infty}\left\|x_{n}-x\right\|<\liminf _{n \rightarrow \infty}\left\|x_{n}-y\right\|
$$

It is well known that all Hilbert spaces and $l_{p}(1<p<\infty)$ spaces have Opial's property while $L_{p}$ spaces $(p \neq 2)$ have not. A family $\left\{T_{i}: i=1,2, \ldots, k\right\}$ of self-mappings of $C$ with $F:=\bigcap_{i=1}^{k} F\left(T_{i}\right) \neq \varnothing$ is said to satisfy the following conditions.

(1) Condition $(\bar{A})$ [22]. If there is a nondecreasing function $f:[0, \infty) \rightarrow[0, \infty)$ with $f(0)=0$ and $f(t)>0$ for all $t \in(0, \infty)$ such that $1 / k \sum_{i=1}^{k}\left\|x-T_{i} x\right\| \geq f(d(x, F))$ for all $x \in C$, where $d(x, F)=\inf \{\|x-p\|: p \in F\}$.

(2) Condition $(\bar{B})$ [22]. If there is a nondecreasing function $f:[0, \infty) \rightarrow[0, \infty)$ with $f(0)=0$ and $f(t)>0$ for all $t \in(0, \infty)$ such that $\max _{1 \leq i \leq k}\left\{\left\|x-T_{i} x\right\|\right\} \geq f(d(x, F))$ for all $x \in C$.

(3) Condition $(\bar{C})$ [22]. If there is a nondecreasing function $f:[0, \infty) \rightarrow[0, \infty)$ with $f(0)=0$ and $f(t)>0$ for all $t \in(0, \infty)$ such that $\left\|x-T_{l} x\right\| \geq f(d(x, F))$ for all $x \in C$ and for at least one $T_{l}, l=1,2, \ldots, k$.

Note that $(\bar{B})$ and $(\bar{C})$ are equivalent, condition $(\bar{B})$ reduces to condition (I) when all but one of $T_{i}{ }^{\prime}$ s are identities, and in addition, it also condition $(\bar{A})$.

It is well known that every continuous and demicompact mapping must satisfy condition (I) (see [4]). Since every completely continuous $T: C \rightarrow C$ is continuous and demicompact so that it satisfies condition (I). Thus we will use condition $(\bar{C})$ instead of the demicompactness and complete continuity of a family $\left\{T_{i}: i=1,2, \ldots, k\right\}$.

Lemma 2.1 (see $[8$, Lemma 1$]$ ). Let $\left\{a_{n}\right\},\left\{b_{n}\right\}$, and $\left\{\delta_{n}\right\}$ be sequences of nonnegative real numbers satisfying the inequality

$$
a_{n+1} \leq\left(1+\delta_{n}\right)_{a_{n}}+b_{n}, \quad \forall n=1,2, \ldots
$$

If $\sum_{n=1}^{\infty} \delta_{n}<\infty$ and $\sum_{n=1}^{\infty} b_{n}<\infty$, then

(i) $\lim _{n \rightarrow \infty} a_{n}$ exists;

(ii) $\lim _{n \rightarrow \infty} a_{n}=0$ whenever $\lim \inf _{n \rightarrow \infty} a_{n}=0$.

Lemma 2.2 (see [7, Lemma 3.1]). Let $X$ be a uniformly convex Banach space, $\left\{x_{n}\right\},\left\{y_{n}\right\} \subset X$, real numbers $a \geq 0, \alpha, \beta \in(0,1)$, and let $\left\{\alpha_{n}\right\}$ be a real sequence number which satisfies

(i) $0<\alpha \leq \alpha_{n} \leq \beta<1$, for all $n \geq n_{0}$ and for some $n_{0} \in \mathbb{N}$;

(ii) $\lim \sup _{n \rightarrow \infty}\left\|x_{n}\right\| \leq a$ and $\lim \sup _{n \rightarrow \infty}\left\|y_{n}\right\| \leq a$;

(iii) $\lim _{n \rightarrow \infty}\left\|\alpha_{n} x_{n}+\left(1-\alpha_{n}\right) y_{n}\right\|=a$. Then $\lim _{n \rightarrow \infty}\left\|x_{n}-y_{n}\right\|=0$. 
Lemma 2.3 (see [14, Lemma 2.7]). Let X be a Banach space which satisfies Opial's property and let $\left\{x_{n}\right\}$ be a sequence in $X$. Let $u, v \in X$ be such that $\lim _{n \rightarrow \infty}\left\|x_{n}-u\right\|$ and $\lim _{n \rightarrow \infty}\left\|x_{n}-v\right\|$ exist. If $\left\{x_{n_{k}}\right\}$ and $\left\{x_{m_{k}}\right\}$ are subsequences of $\left\{x_{n}\right\}$ which converge weakly to $u$ and $v$, respectively, then $u=v$.

\section{Convergence Theorems in Banach Spaces}

Our first result is the strong convergence theorems of the iterative scheme (1.7) for a finite family of generalized asymptotically quasi-nonexpansive mappings in a Banach space. In order to prove our main results, the following lemma is needed.

Lemma 3.1. Let $X$ be a Banach space and $C$ a nonempty closed and convex subset of $X$, and $\left\{T_{i}: i=\right.$ $1,2, \ldots, k\}$ a finite family of generalized asymptotically quasi-nonexpansive self-mappings of $C$ with the sequences $\left\{b_{i n}\right\},\left\{c_{i n}\right\} \subset[0, \infty)$ such that $\sum_{n=1}^{\infty} b_{i n}<\infty$ and $\sum_{n=1}^{\infty} c_{i n}<\infty$ for all $i=1,2, \ldots, k$. Assume that $F \neq \varnothing$ and $\sum_{n=1}^{\infty} \gamma_{i n}<\infty$ for each $i=1,2, \ldots, k$. For a given $x_{1} \in C$, let the sequences $\left\{x_{n}\right\}$ and $\left\{y_{i n}\right\}$ be defined by (1.7). Then

(a) there exist sequences $\left\{v_{n}\right\}$ and $\left\{e_{i n}\right\}$ in $[0, \infty)$ such that $\sum_{n=1}^{\infty} v_{n}<\infty, \sum_{n=1}^{\infty} e_{i n}<\infty$, and $\left\|y_{\text {in }}-p\right\| \leq\left(1+v_{n}\right)^{i}\left\|x_{n}-p\right\|+e_{\text {in }}$, for all $i=1,2, \ldots, k$ and all $p \in F$

(b) $\lim _{n \rightarrow \infty}\left\|x_{n}-p\right\|$ exists for all $p \in F$;

(c) there exist constant $M>0$ and $\left\{s_{i}\right\}$ in $[0, \infty)$ such that $\sum_{i=1}^{\infty} s_{i}<\infty$ and $\left\|x_{n+m}-p\right\| \leq$ $M\left\|x_{n}-p\right\|+\sum_{i=n}^{\infty} s_{i}$ for all $p \in F$ and $n, m \in \mathbb{N}$.

Proof. (a) Let $p \in F, v_{n}=\max _{1 \leq i \leq k}\left\{b_{i n}\right\}$ and $d_{n}=\max _{1 \leq i \leq k}\left\{c_{i n}\right\}$ for all $n$.

Since $\sum_{n=1}^{\infty} b_{i n}<\infty$ and $\sum_{n=1}^{\infty} c_{i n}<\infty$, for all $i=1,2, \ldots, k$, therefore $\sum_{n=1}^{\infty} v_{n}<\infty$ and $\sum_{n=1}^{\infty} d_{n}<\infty$. For each $n \geq 1$, we note that

$$
\begin{aligned}
\left\|y_{1 n}-p\right\| & =\left\|\alpha_{1 n} T_{1}^{n} y_{0 n}+\beta_{1 n} x_{n}+\gamma_{1 n} u_{1 n}-p\right\| \\
& \leq \alpha_{1 n}\left\|T_{1}^{n} x_{n}-p\right\|+\beta_{1 n}\left\|x_{n}-p\right\|+\gamma_{1 n}\left\|u_{1 n}-p\right\| \\
& \leq \alpha_{1 n}\left(1+b_{1 n}\right)\left\|x_{n}-p\right\|+\alpha_{1 n} c_{1 n}+\beta_{1 n}\left\|x_{n}-p\right\|+\gamma_{1 n}\left\|u_{1 n}-p\right\| \\
& \leq \alpha_{1 n}\left(1+v_{n}\right)\left\|x_{n}-p\right\|+\alpha_{1 n} d_{n}+\beta_{1 n}\left(1+v_{n}\right)\left\|x_{n}-p\right\|+\gamma_{1 n}\left\|u_{1 n}-p\right\| \\
& \leq\left(1+v_{n}\right)\left\|x_{n}-p\right\|+e_{1 n},
\end{aligned}
$$

where $e_{1 n}=\alpha_{1 n} d_{n}+\gamma_{1 n}\left\|u_{1 n}-p\right\|$. Since $\left\{u_{1 n}\right\}$ is bounded, $\sum_{n=1}^{\infty} \gamma_{1 n}<\infty$ and $\sum_{n=1}^{\infty} d_{n}<\infty$, we obtain that $\sum_{n=1}^{\infty} e_{1 n}<\infty$. It follows from (3.1) that

$$
\begin{aligned}
\left\|y_{2 n}-p\right\| & \leq \alpha_{2 n}\left\|T_{2}^{n} y_{1 n}-p\right\|+\beta_{2 n}\left\|x_{n}-p\right\|+\gamma_{2 n}\left\|u_{2 n}-p\right\| \\
& \leq \alpha_{2 n}\left(1+v_{n}\right)\left\|y_{1 n}-p\right\|+\alpha_{2 n} d_{n}+\beta_{2 n}\left\|x_{n}-p\right\|+\gamma_{2 n}\left\|u_{2 n}-p\right\| \\
& \leq \alpha_{2 n}\left(1+v_{n}\right)\left(\left(1+v_{n}\right)\left\|x_{n}-p\right\|+e_{1 n}\right)+\alpha_{2 n} d_{n}+\beta_{2 n}\left(1+v_{n}\right)^{2}\left\|x_{n}-p\right\|+\gamma_{2 n}\left\|u_{2 n}-p\right\| \\
& =\left(\alpha_{2 n}+\beta_{2 n}\right)\left(1+v_{n}\right)^{2}\left\|x_{n}-p\right\|+\alpha_{2 n}\left(1+v_{n}\right) e_{1 n}+\alpha_{2 n} d_{n}+\gamma_{2 n}\left\|u_{2 n}-p\right\| \\
& \leq\left(1+v_{n}\right)^{2}\left\|x_{n}-p\right\|+e_{2 n},
\end{aligned}
$$


where $e_{2 n}=\alpha_{2 n}\left(1+v_{n}\right) e_{1 n}+\alpha_{2 n} d_{n}+\gamma_{2 n}\left\|u_{2 n}-p\right\|$. Since $\left\{u_{2 n}\right\},\left\{v_{n}\right\}$ are bounded, $\sum_{n=1}^{\infty} e_{1 n}<\infty$, $\sum_{n=1}^{\infty} d_{n}<\infty$, and $\sum_{n=1}^{\infty} \gamma_{2 n}<\infty$, it follows that $\sum_{n=1}^{\infty} e_{2 n}<\infty$. Moreover, we see that

$$
\begin{aligned}
\left\|y_{3 n}-p\right\| & \leq \alpha_{3 n}\left\|T_{3}^{n} y_{2 n}-p\right\|+\beta_{3 n}\left\|x_{n}-p\right\|+\gamma_{3 n}\left\|u_{3 n}-p\right\| \\
& \leq \alpha_{3 n}\left(1+v_{n}\right)\left\|y_{2 n}-p\right\|+\alpha_{3 n} d_{n}+\beta_{3 n}\left\|x_{n}-p\right\|+\gamma_{3 n}\left\|u_{3 n}-p\right\| \\
& \leq \alpha_{3 n}\left(1+v_{n}\right)\left(\left(1+v_{n}\right)^{2}\left\|x_{n}-p\right\|+e_{2 n}\right)+\alpha_{3 n} d_{n}+\beta_{3 n}\left(1+v_{n}\right)^{3}\left\|x_{n}-p\right\|+\gamma_{3 n}\left\|u_{3 n}-p\right\| \\
& =\left(\alpha_{3 n}+\beta_{3 n}\right)\left(1+v_{n}\right)^{3}\left\|x_{n}-p\right\|+\alpha_{3 n}\left(1+v_{n}\right) e_{2 n}+\alpha_{3 n} d_{n}+\gamma_{3 n}\left\|u_{3 n}-p\right\| \\
& \leq\left(1+v_{n}\right)^{3}\left\|x_{n}-p\right\|+e_{3 n},
\end{aligned}
$$

where $e_{3 n}=\alpha_{3 n}\left(1+v_{n}\right) e_{2 n}+\alpha_{3 n} d_{n}+\gamma_{3 n}\left\|u_{3 n}-p\right\|$. Since $\left\{u_{3 n}\right\},\left\{v_{n}\right\}$ are bounded, $\sum_{n=1}^{\infty} e_{2 n}<$ $\infty, \sum_{n=1}^{\infty} d_{n}<\infty$, and $\sum_{n=1}^{\infty} \gamma_{3 n}<\infty$, it follows that $\sum_{n=1}^{\infty} e_{3 n}<\infty$. By continuing the above method, there are nonnegative real sequences $\left\{e_{i n}\right\}$ in $[0, \infty)$ such that $\sum_{n=1}^{\infty} e_{i n}<\infty$ and

$$
\left\|y_{\text {in }}-p\right\| \leq\left(1+v_{n}\right)^{i}\left\|x_{n}-p\right\|+e_{\text {in }} \quad \forall i=1,2, \ldots, k
$$

This completes the proof of (a).

(b) From part (a), for the case $i=k$, we have

$$
\left\|x_{n+1}-p\right\| \leq\left(1+v_{n}\right)^{k}\left\|x_{n}-p\right\|+e_{k n}, \quad \forall n, p \in F
$$

It follows from Lemma 2.1(i) that $\lim _{n \rightarrow \infty}\left\|x_{n}-p\right\|$ exists, for all $p \in F$. follows that

(c) If $t \geq 0$, then $1+t \leq e^{t}$ and so, $(1+t)^{k} \leq e^{k t}$, for $k=1,2, \ldots$ Thus, from (3.5), it

$$
\begin{aligned}
\left\|x_{n+m}-p\right\| & \leq\left(1+v_{n+m-1}\right)^{k}\left\|x_{n+m-1}-p\right\|+e_{k(n+m-1)} \\
& \leq \exp \left\{k v_{n+m-1}\right\}\left\|x_{n+m-1}-p\right\|+e_{k(n+m-1)} \\
& \leq \cdots \leq \exp \left\{k \sum_{i=n}^{n+m-1} v_{i}\right\}\left\|x_{n}-p\right\|+\sum_{i=n}^{n+m-1} e_{k i} \\
& \leq \exp \left\{k \sum_{i=1}^{\infty} v_{i}\right\}\left\|x_{n}-p\right\|+\sum_{i=n}^{\infty} e_{k i} \\
& \leq M\left\|x_{n}-p\right\|+\sum_{i=n}^{\infty} s_{i}
\end{aligned}
$$

where $M=\exp \left\{k \sum_{i=1}^{\infty} v_{i}\right\}$ and $s_{i}=e_{k i}$. 
Theorem 3.2. Let $X$ be a Banach space and $C$ a nonempty closed and convex subset of $X$ and $\left\{T_{i}: i=\right.$ $1,2, \ldots, k\}$ a finite family of generalized asymptotically quasi-nonexpansive self-mappings of $C$ with the sequences $\left\{b_{i n}\right\},\left\{c_{i n}\right\} \subset[0, \infty)$ such that $\sum_{n=1}^{\infty} b_{i n}<\infty$ and $\sum_{n=1}^{\infty} c_{i n}<\infty$ for all $i=1,2, \ldots, k$. Assume that $F \neq \emptyset$ is closed and $\sum_{n=1}^{\infty} \gamma_{i n}<\infty$ for each $i=1,2, \ldots, k$. Then the iterative sequence $\left\{x_{n}\right\}$ defined by (1.7) converges strongly to a common fixed point of the family of mappings if and only if $\lim \inf _{n \rightarrow \infty} d\left(x_{n}, F\right)=0$.

Proof. We prove only the sufficiency because the necessity is obvious. From (3.5), we have $\left\|x_{n+1}-p\right\| \leq\left(1+v_{n}\right)^{k}\left\|x_{n}-p\right\|+e_{k n}$, for all $n$ and all $p \in F$.

Hence, we have

$$
\begin{aligned}
d\left(x_{n+1}, F\right) & \leq\left(1+v_{n}\right)^{k} d\left(x_{n}, F\right)+e_{k n} \\
& =\left(1+\sum_{r=1}^{k} \frac{k(k-1) \ldots(k-r+1)}{r !} v_{n}^{r}\right) d\left(x_{n}, F\right)+e_{k n} .
\end{aligned}
$$

Since $\sum_{n=1}^{\infty} v_{n}<\infty$, it follows that $\sum_{n=1}^{\infty} \sum_{r=1}^{k}(k(k-1) \cdots(k-r+1) / r !) v_{n}^{r}<\infty$. Since $\sum_{n=1}^{\infty} e_{k n}<$ $\infty$ and $\lim _{\inf _{n \rightarrow \infty}} d\left(x_{n}, F\right)=0$, it follows from Lemma 2.1(ii) that $\lim _{n \rightarrow \infty} d\left(x_{n}, F\right)=0$. Next, we prove that $\left\{x_{n}\right\}$ is a Cauchy sequence. From Lemma 3.1(c), we have

$$
\left\|x_{n+m}-p\right\| \leq M\left\|x_{n}-p\right\|+\sum_{i=n}^{\infty} s_{i}, \quad \forall p \in F, n, m \in \mathbb{N} .
$$

Since $\lim _{n \rightarrow \infty} d\left(x_{n}, F\right)=0$ and $\sum_{i=1}^{\infty} s_{i}<\infty$, therefore for $\epsilon>0$, there exists $n_{0} \in \mathbb{N}$ such that

$$
d\left(x_{n}, F\right)<\frac{\epsilon}{4 M}, \quad \sum_{i=n_{0}}^{\infty} s_{i}<\frac{\epsilon}{4}, \quad \forall n \geq n_{0} .
$$

Therefore, there exists $z_{1}$ in $F$ such that

$$
\left\|x_{n_{0}}-z_{1}\right\|<\frac{\epsilon}{4 M}
$$

From (3.8) to (3.10), for all $n \geq n_{0}$ and $m \geq 1$, we have

$$
\begin{aligned}
\left\|x_{n+m}-x_{n}\right\| & \leq\left\|x_{n+m}-z_{1}\right\|+\left\|x_{n}-z_{1}\right\| \\
& \leq M\left\|x_{n_{0}}-z_{1}\right\|+\sum_{i=n_{0}}^{\infty} s_{i}+M\left\|x_{n_{0}}-z_{1}\right\|+\sum_{i=n_{0}}^{\infty} s_{i} \\
& <M \frac{\epsilon}{4 M}+\frac{\epsilon}{4}+M \frac{\epsilon}{4 M}+\frac{\epsilon}{4}=\epsilon .
\end{aligned}
$$

This shows that $\left\{x_{n}\right\}$ is a Cauchy sequence, hence $x_{n} \rightarrow z \in C$. It remains to show that $z \in F$. Notice that

$$
\left|d(z, F)-d\left(x_{n}, F\right)\right| \leq\left\|z-x_{n}\right\|, \quad \forall n
$$

Since $\lim _{n \rightarrow \infty} d\left(x_{n}, F\right)=0$, we obtain that $z \in F$. 
The following corollary follows from Theorem 3.2.

Corollary 3.3. Let $X$ be a Banach space and $C$ a nonempty closed and convex subset of $X$ and $\left\{T_{i}: i=\right.$ $1,2, \ldots, k\}$ a finite family of generalized asymptotically quasi-nonexpansive self-mappings of $C$ with the sequences $\left\{b_{i n}\right\},\left\{c_{i n}\right\} \subset[0, \infty)$ such that $\sum_{n=1}^{\infty} b_{i n}<\infty$ and $\sum_{n=1}^{\infty} c_{i n}<\infty$ for all $i=1,2, \ldots, k$. Assume that $F \neq \emptyset$ is closed and $\sum_{n=1}^{\infty} \gamma_{i n}<\infty$ for each $i=1,2, \ldots, k$. Then the iterative sequence $\left\{x_{n}\right\}$, defined by (1.7), converges strongly to a point $p \in F$ if and only if there exists a subsequence $\left\{x_{n_{j}}\right\}$ of $\left\{x_{n}\right\}$ converging to $p$.

Since an asymptotically quasi-nonexpansive mapping is generalized asymptotically quasi-nonexpansive mapping, so we have the following result.

Corollary 3.4. Let $X$ be a Banach space and $C$ a nonempty closed and convex subset of $X$ and $\left\{T_{i}: i=\right.$ $1,2, \ldots, k\}$ a finite family of asymptotically quasi-nonexpansive self-mappings of $C$ with the sequences $\left\{b_{i n}\right\} \subset[0, \infty)$ such that $\sum_{n=1}^{\infty} b_{i n}<\infty$ for all $i=1,2, \ldots, k$. Assume that $F \neq \varnothing$ and $\sum_{n=1}^{\infty} \gamma_{\text {in }}<\infty$ for each $i=1,2, \ldots, k$. Then the iterative sequence $\left\{x_{n}\right\}$, defined by (1.7), converges strongly to $a$ common fixed point of the family of mappings if and only if $\lim _{\inf _{n \rightarrow \infty}} d\left(x_{n}, F\right)=0$.

Remark 3.5. Theorem 3.2 generalizes and extends Theorem 2.2 of Khan et al. [6], for a finite family of asymptotically quasi-nonexpansive mappings, Theorem 1 of Fukhar-ud-din and Khan [5], and Theorem 3.2 of Shahzad and Udomene [10] for two asymptotically quasinonexpanaive mappings to the more general class of generalized asymptotically quasinonexpansive mappings.

Theorem 3.6. Let $X$ be a Banach space and $C$ a nonempty closed and convex subset of $X$ and $\left\{T_{i}: i=\right.$ $1,2, \ldots, k\}$ a finite family of generalized asymptotically quasi-nonexpansive self-mappings of $C$ with the sequences $\left\{b_{i n}\right\},\left\{c_{i n}\right\} \subset[0, \infty)$ such that $\sum_{n=1}^{\infty} b_{i n}<\infty$ and $\sum_{n=1}^{\infty} c_{i n}<\infty$ for all $i=1,2, \ldots, k$. Suppose that $F \neq \emptyset$ is closed. Let $x_{1} \in C$ and $\left\{x_{n}\right\}$ be the sequence defined by (1.7). If $\sum_{n=1}^{\infty} \gamma_{i n}<\infty$, $\lim _{n \rightarrow \infty}\left\|x_{n}-T_{i} x_{n}\right\|=0$ for all $i=1,2, \ldots, k$ and $\left\{T_{i}: i=1,2, \ldots, k\right\}$ satisfies condition $(\bar{C})$, then $\left\{x_{n}\right\}$ converges strongly to a common fixed point of the family of mappings.

Proof. From $\lim _{n \rightarrow \infty}\left\|x_{n}-T_{i} x_{n}\right\|=0$ for all $i=1,2, \ldots, k$ and $\left\{T_{i}: i=1,2, \ldots, k\right\}$ satisfying condition $(\bar{C})$, there is a nondecreasing function $f:[0, \infty) \rightarrow[0, \infty)$ with $f(0)=0$ and $f(t)>0$ for all $t \in(0, \infty)$ such that $\left\|x_{n}-T_{i_{0}} x_{n}\right\| \geq f\left(d\left(x_{n}, F\right)\right)$ for some $i_{0} \in\{1,2, \ldots, k\}$, it follows that $\lim _{n \rightarrow \infty} d\left(x_{n}, F\right)=0$. From Theorem 3.2, we obtain that $\left\{x_{n}\right\}$ converges strongly to a common fixed point of the family of mappings.

\section{Convergence Theorems in Uniformly Convex Banach Spaces}

In this section, we establish weak and strong convergence theorems of the iterative scheme (1.7) for a finite family of generalized asymptotically quasi-nonexpansive and $(L-\gamma)$ uniform Lipschitz mappings in a uniformly convex Banach space. In order to prove our main results, we need the following lemma.

Lemma 4.1. Let $C$ be a nonempty closed and convex subset of a uniformly convex Banach space $X$ and $\left\{T_{i}, i=1,2, \ldots, k\right\}$ a finite family of $(L-\gamma)$ uniform Lipschitz and generalized asymptotically quasinonexpansive self-mappings of $C$ with the sequences $\left\{b_{i n}\right\},\left\{c_{i n}\right\} \subset[0, \infty)$ such that $\sum_{n=1}^{\infty} b_{i n}<\infty$ and $\sum_{n=1}^{\infty} c_{i n}<\infty$ for all $i=1,2, \ldots, k$. Assume that $F \neq \varnothing$ and $\sum_{n=1}^{\infty} \gamma_{i n}<\infty$ for all $i=1,2, \ldots, k$. For a given $x_{1} \in C$ let $\left\{x_{n}\right\}$ and $\left\{y_{i n}\right\}$ be the sequences defined by (1.7) with $0<\eta \leq \alpha_{\text {in }} \leq \rho<1$, 
for all $i=1,2, \ldots, k$ and all $n \geq n_{0}$ and for some $n_{0} \in \mathbb{N}$. Then

(i) $\lim _{n \rightarrow \infty}\left\|T_{j}^{n} y_{(j-1) n}-x_{n}\right\|=0$ for all $j=1,2, \ldots, k$,

(ii) $\lim _{n \rightarrow \infty}\left\|T_{j} x_{n}-x_{n}\right\|=0$ for all $j=1,2, \ldots, k$,

(iii) $\lim _{n \rightarrow \infty}\left\|y_{j n}-x_{n}\right\|=0$ for all $j=1,2, \ldots, k$.

Proof. Let $p \in F, v_{n}=\max _{1 \leq i \leq k}\left\{b_{i n}\right\}$ and $d_{n}=\max _{1 \leq i \leq k}\left\{c_{i n}\right\}$ for all $n$.

(i) From Lemma 3.1(b), we have that $\lim _{n \rightarrow \infty}\left\|x_{n}-p\right\|$ exists for all $p \in F$. Suppose that

$$
\lim _{n \rightarrow \infty}\left\|x_{n}-p\right\|=a
$$

From (3.4) and (4.1), we get that

$$
\limsup _{n \rightarrow \infty}\left\|y_{j n}-p\right\| \leq a, \quad \text { for } 1 \leq j \leq k-1 .
$$

For each $j \in\{1,2, \ldots, k-1\}$ and $n \in \mathbb{N}$, we have

$$
\begin{aligned}
\left\|y_{j n}-p\right\| \leq & \alpha_{j n}\left\|T_{j}^{n} y_{(j-1) n}-p\right\|+\beta_{j n}\left\|x_{n}-p\right\|+\gamma_{j n}\left\|u_{j n}-p\right\| \\
\leq & \alpha_{j n}\left(1+v_{n}\right)\left\|y_{(j-1) n}-p\right\|+\alpha_{j n}\left(1+v_{n}\right) d_{n} \\
& +\left(1-\alpha_{j n}\right)\left(1+v_{n}\right)\left\|x_{n}-p\right\|+\gamma_{j n}\left(1+v_{n}\right)\left\|u_{j n}-p\right\| .
\end{aligned}
$$

By using (4.3) and (1.7), for each $j=1,2, \ldots, k-1$, we have

$$
\begin{aligned}
\left\|x_{n+1}-p\right\|= & \left\|\alpha_{k n}\left(T_{k}^{n} y_{(k-1) n}-p\right)+\beta_{k n}\left(x_{n}-p\right)+\gamma_{k n}\left(u_{k n}-p\right)\right\| \\
\leq & \alpha_{k n}\left(1+v_{n}\right)\left\|y_{(k-1) n}-p\right\|+\left(1-\alpha_{k n}\right)\left(1+v_{n}\right)\left\|x_{n}-p\right\| \\
& +\alpha_{k n}\left(1+v_{n}\right) d_{n}+\gamma_{k n}\left\|u_{k n}-p\right\|\left(1+v_{n}\right) \\
\leq & \left(\alpha_{k n} \alpha_{(k-1) n}\right)\left(1+v_{n}\right)^{2}\left\|y_{(k-2) n}-p\right\| \\
& +\left(1-\alpha_{k n} \alpha_{(k-1) n}\right)\left(1+v_{n}\right)^{2}\left\|x_{n}-p\right\|+\left(\alpha_{k n}+\alpha_{(k-1) n}\right)\left(1+v_{n}\right)^{2} d_{n} \\
& +\left(\gamma_{k n}\left\|u_{k n}-p\right\|+\gamma_{(k-1) n}\left\|u_{(k-1) n}-p\right\|\right)\left(1+v_{n}\right)^{2} \\
& \vdots \\
\leq & \left(\alpha_{k n} \alpha_{(k-1) n} \cdots \alpha_{(j+1) n}\right)\left(1+v_{n}\right)^{(k-j)}\left\|y_{j n}-p\right\| \\
& +\left(1-\alpha_{k n} \alpha_{(k-1) n} \cdots \alpha_{(j+1) n}\right)\left(1+v_{n}\right)^{(k-j)}\left\|x_{n}-p\right\| \\
& +\left(\alpha_{k n}+\alpha_{(k-1) n}+\cdots+\alpha_{(j+1) n}\right)\left(1+v_{n}\right)^{(k-j)} d_{n} \\
& +\left(\gamma_{k n}\left\|u_{k n}-p\right\|+\gamma_{(k-1) n}\left\|u_{(k-1) n}-p\right\|+\cdots+\gamma_{(j+1) n}\left\|u_{(j+1) n}-p\right\|\right)\left(1+v_{n}\right)^{k-j} .
\end{aligned}
$$


Since $0<\eta \leq \alpha_{i n} \leq \rho<1$, for all $i=1,2, \ldots, k$ and all $n \geq n_{0}$, we have that for all $n \geq n_{0}$ and all $j=1,2, \ldots, k-1$,

$$
\left\|x_{n}-p\right\| \leq \frac{\left\|x_{n}-p\right\|}{\eta^{k-j}}-\frac{\left\|x_{n+1}-p\right\|}{\eta^{k-j}\left(1+v_{n}\right)^{k-j}}+\left\|y_{j n}-p\right\|+\frac{\xi_{j n}}{\eta^{k-j}} d_{n}+\frac{\vartheta_{j n}}{\eta^{k-j}}
$$

where $\xi_{j n}=\alpha_{k n}+\alpha_{(k-1) n}+\cdots+\alpha_{(j+1) n}$ and $\vartheta_{j n}=\gamma_{k n}\left\|u_{k n}-p\right\|+\gamma_{(k-1) n}\left\|u_{(k-1) n}-p\right\|+\cdots+$ $\gamma_{(j+1) n}\left\|u_{(j+1) n}-p\right\|$. Since $\lim _{n \rightarrow \infty}\left\|x_{n}-p\right\|=a$ and $\lim _{n \rightarrow \infty} \vartheta_{j n}=\lim _{n \rightarrow \infty} d_{n}=\lim _{n \rightarrow \infty} v_{n}=0$, it follows that

$$
a \leq \liminf _{n \rightarrow \infty}\left\|y_{j n}-p\right\|, \quad \forall j=1,2, \ldots, k-1
$$

From (4.2) and (4.6), we have

$$
\lim _{n \rightarrow \infty}\left\|y_{j n}-p\right\|=a=\lim _{n \rightarrow \infty}\left\|x_{n}-p\right\|, \quad \forall j=1,2, \ldots, k-1
$$

That is, for each $j=1,2, \ldots, k$, we have

$$
\lim _{n \rightarrow \infty}\left\|\alpha_{j n}\left(T_{j}^{n} y_{(j-1) n}-p+\gamma_{j n}\left(u_{j n}-x_{n}\right)\right)+\left(1-\alpha_{j n}\right)\left(x_{n}-p+\gamma_{j n}\left(u_{j n}-x_{n}\right)\right)\right\|=a .
$$

Since

$$
\begin{aligned}
\left\|T_{j}^{n} y_{(j-1) n}-p+\gamma_{j n}\left(u_{j n}-x_{n}\right)\right\| & \leq\left\|T_{j}^{n} y_{(j-1) n}-p\right\|+\gamma_{j n}\left\|u_{j n}-x_{n}\right\| \\
& \leq\left(1+v_{n}\right)\left\|y_{(j-1) n}-p\right\|+d_{n}+\gamma_{j n}\left\|u_{j n}-x_{n}\right\|, \\
\left\|x_{n}-p+\gamma_{j n}\left(u_{j n}-x_{n}\right)\right\| & \leq\left\|x_{n}-p\right\|+\gamma_{j n}\left\|u_{j n}-x_{n}\right\|
\end{aligned}
$$

it follows that

$$
\begin{gathered}
\limsup _{n \rightarrow \infty}\left\|T_{j}^{n} y_{(j-1) n}-p+\gamma_{j n}\left(u_{j n}-x_{n}\right)\right\| \leq a, \\
\limsup _{n \rightarrow \infty}\left\|x_{n}-p+\gamma_{j n}\left(u_{j n}-x_{n}\right)\right\| \leq a, \quad \forall j=1,2, \ldots, k .
\end{gathered}
$$

From (4.8) to (4.11), we can conclude from Lemma 2.2 that

$$
\lim _{n \rightarrow \infty}\left\|T_{j}^{n} y_{(j-1) n}-x_{n}\right\|=0, \quad \forall j=1,2, \ldots, k
$$


(ii) It follows from part (i) in the case $j=1$ that $\lim _{n \rightarrow \infty}\left\|T_{1}^{n} x_{n}-x_{n}\right\|=0$. For $j=$ $2,3, \ldots, k$, we obtain from part (i) that

$$
\begin{aligned}
\left\|T_{j}^{n} x_{n}-x_{n}\right\| \leq & \left\|T_{j}^{n} x_{n}-T_{j}^{n} y_{(j-1) n}\right\|+\left\|T_{j}^{n} y_{(j-1) n}-x_{n}\right\| \\
\leq & L\left\|x_{n}-y_{(j-1) n}\right\|^{\gamma}+\left\|T_{j}^{n} y_{(j-1) n}-x_{n}\right\| \\
\leq & L\left(\alpha_{(j-1) n}\left\|T_{j-1}^{n} y_{(j-2) n}-x_{n}\right\|+\gamma_{(j-1) n}\left\|u_{(j-1) n}-x_{n}\right\|\right)^{\gamma} \\
& +\left\|T_{j}^{n} y_{(j-1) n}-x_{n}\right\| \rightarrow 0 \text { as } n \rightarrow \infty .
\end{aligned}
$$

Therefore,

$$
\lim _{n \rightarrow \infty}\left\|T_{j}^{n} x_{n}-x_{n}\right\|=0, \quad \forall j=1,2, \ldots, k .
$$

Since

$$
\begin{aligned}
\left\|x_{n}-T_{j} x_{n}\right\| \leq & \left\|x_{n+1}-x_{n}\right\|+\left\|x_{n+1}-T_{j}^{n+1} x_{n+1}\right\| \\
& +\left\|T_{j}^{n+1} x_{n+1}-T_{j}^{n+1} x_{n}\right\|+\left\|T_{j}^{n+1} x_{n}-T_{j} x_{n}\right\| \\
\leq & \alpha_{k n}\left\|T_{k}^{n} y_{(k-1) n}-x_{n}\right\|+\gamma_{k n}\left\|u_{k n}-x_{n}\right\|+\left\|x_{n+1}-T_{j}^{n+1} x_{n+1}\right\| \\
& +L\left(\alpha_{k n}\left\|T_{k}^{n} y_{(k-1) n}-x_{n}\right\|+\gamma_{k n}\left\|u_{k n}-x_{n}\right\|\right)^{\gamma}+L\left\|T_{j}^{n} x_{n}-x_{n}\right\|^{\gamma},
\end{aligned}
$$

it follows from (i) and (4.14) that

$$
\lim _{n \rightarrow \infty}\left\|T_{j} x_{n}-x_{n}\right\|=0, \quad \forall j=1,2, \ldots, k
$$

(iii) Since $\lim _{n \rightarrow \infty} \gamma_{j n}=0$ and

$$
\left\|y_{j n}-x_{n}\right\| \leq \alpha_{j n}\left\|T_{j}^{n} y_{(j-1) n}-x_{n}\right\|+\gamma_{j n}\left\|u_{j n}-x_{n}\right\|
$$

for all $j \in\{1,2, \ldots, k\}$, (iii) is directly obtained by (i).

Theorem 4.2. Let $C$ be a nonempty closed and convex subset of a uniformly convex Banach space $X$ satisfying the Opial's property, and $\left\{T_{i}, i=1,2, \ldots, k\right\}$ a finite family of $(L-\gamma)$ uniform Lipschitz and generalized asymptotically quasi-nonexpansive self-mappings of $C$ with the sequences $\left\{b_{i n}\right\},\left\{c_{i n}\right\} \subset$ $[0, \infty)$ such that $\sum_{n=1}^{\infty} b_{i n}<\infty$ and $\sum_{n=1}^{\infty} c_{i n}<\infty$ for all $i=1,2, \ldots, k$. Assume that $F \neq \varnothing$ and $\sum_{n=1}^{\infty} \gamma_{\text {in }}<\infty$ for all $i=1,2, \ldots, k$. For a given $x_{1} \in C$ let $\left\{x_{n}\right\}$ be the sequence defined by (1.7) with $0<\eta \leq \alpha_{i n} \leq \rho<1$, for all $i=1,2, \ldots, k$ and all $n \geq n_{0}$ and for some $n_{0} \in \mathbb{N}$. If $I-T_{i}$, $i=1,2, \ldots, k$, is demiclosed at 0 , then $\left\{x_{n}\right\}$ converges weakly to a common fixed point of the family $\left\{T_{i}: i=1,2, \ldots, k\right\}$. 
Proof. By Lemma 4.1(ii), we have $\lim _{n \rightarrow \infty}\left\|T_{i} x_{n}-x_{n}\right\|=0$, for all $i=1,2, \ldots, k$. Since $X$ is uniformly convex and $\left\{x_{n}\right\}$ is bounded, without loss of generality we may assume that $x_{n} \rightarrow$ $u$ weakly as $n \rightarrow \infty$ for some $u \in C$. Since $I-T_{i}, i=1,2, \ldots, k$, is demiclosed at 0 , we have $u \in F$. Suppose that there are subsequences $\left\{x_{n_{k}}\right\}$ and $\left\{x_{m_{k}}\right\}$ of $\left\{x_{n}\right\}$ that converge weakly to $u$ and $v$, respectively. Again, as above, we can prove that $u, v \in F$. By Lemma 3.1(b), $\lim _{n \rightarrow \infty}\left\|x_{n}-u\right\|$ and $\lim _{n \rightarrow \infty}\left\|x_{n}-v\right\|$ exist. It follows from Lemma 2.3 that $u=v$. Therefore $\left\{x_{n}\right\}$ converges weakly to a common fixed point of $\left\{T_{i}: i=1,2, \ldots, k\right\}$.

Theorem 4.3. Under the hypotheses of Lemma 4.1, assume that the family $\left\{T_{i}: i=1,2, \ldots, k\right\}$ satisfies condition $(\bar{C})$. Then $\left\{x_{n}\right\}$ and $\left\{y_{j n}\right\}$ converge strongly to a common fixed point of the family of mappings for all $j=1,2, \ldots, k$.

Proof. From (3.5), we have

$$
\left\|x_{n+1}-p\right\| \leq\left(1+v_{n}\right)^{k}\left\|x_{n}-p\right\|+e_{k n}, \quad \forall n, p \in F .
$$

Therefore,

$$
\begin{aligned}
d\left(x_{n+1}, F\right) & \leq\left(1+v_{n}\right)^{k} d\left(x_{n}, F\right)+e_{k n} \\
& =\left(1+\sum_{r=1}^{k} \frac{k(k-1) \cdots(k-r+1)}{r !} v_{n}^{r}\right) d\left(x_{n}, F\right)+e_{k n}
\end{aligned}
$$

Since $\sum_{n=1}^{\infty} v_{n}<\infty$, it follows that $\sum_{n=1}^{\infty} \sum_{r=1}^{k}(k(k-1) \cdots(k-r+1) / r !) v_{n}^{r}<\infty$. Since $\sum_{n=1}^{\infty} e_{k n}<\infty$, we obtain from Lemma 2.1(i) that $\lim _{n \rightarrow \infty} d\left(x_{n}, F\right)$ exists. By Lemma 4.1(ii), we have $\lim _{n \rightarrow \infty}\left\|T_{i} x_{n}-x_{n}\right\|=0$ for all $i=1,2, \ldots, k$. Since $\left\{T_{i}: i=1,2, \ldots, k\right\}$ satisfies condition $(\bar{C})$, there is a nondecreasing function $f:[0, \infty) \rightarrow[0, \infty)$ with $f(0)=0$ and $f(t)>0$ for all $t \in(0, \infty)$ such that $\left\|x_{n}-T_{i_{0}} x_{n}\right\| \geq f\left(d\left(x_{n}, F\right)\right)$ for some $i_{0} \in\{1,2, \ldots, k\}$, it follows that $\lim _{n \rightarrow \infty} d\left(x_{n}, F\right)=0$. By Theorem 3.2, we can conclude that $\left\{x_{n}\right\}$ converges strongly to a common fixed point $q$ of the family $\left\{T_{i}: i=1,2, \ldots, k\right\}$. From Lemma 4.1(iii), we have $\lim _{n \rightarrow \infty}\left\|y_{j n}-x_{n}\right\|=0$ for all $j=1,2, \ldots, k$, and we obtain that $\lim _{n \rightarrow \infty} y_{j n}=q$ for all $j=1,2, \ldots, k$.

Remark 4.4. The family of generalized asymptotically quasi-nonexpansive mappings in Theorem 4.2 and 4.3 can be replaced by a family of asymptotically quasi-nonexpansive mappings. Lemma 3.1 and 4.1 generalize and improve [6, Lemma 3.1], [19, Lemmas 3.4 and 3.5], [18, Lemma 2.3], [7, Lemma 4.2], and [17, Lemma 3.3] to a finite family of $(L-\gamma)$ uniform Lipschitz and generalized asymptotically quasi-nonexpansive mappings. Theorem 4.2 generalizes and improves [6, Theorems 3.2 and 4.2], [18, Theorem 2.9], [17, Theorem 3.1], and [21, Theorem 1] to the more general class of a finite family of $(L-\gamma)$ uniform Lipschitz and generalized asymptotically quasi-nonexpansive mappings. Theorem 4.3 generalizes and improves [6, Theorem 3.3], [7, Theorem 4.3], [5, Theorem 2], [18, Theorem 2.4], [19, Theorem 4.2], [17, Theorem 3.2], [10, Theorem 3.4], [20, Theorem 2] and [21, Theorem 2] by using condition $(\bar{C})$ instead of condition $(\bar{A})$ or semicompactness or completely continuous or compactness to the more general class of a finite family of $(L-\gamma)$ uniform Lipschitz and generalized asymptotically quasi-nonexpansive mappings.

Remark 4.5. From Remark 1.1, Theorems 3.2 to 4.3 hold true for a finite family $\left\{T_{i}\right\}_{i=1}^{k}$ of asymptotically nonexpansive mappings in the intermediate sense. 


\section{Acknowledgments}

The authors would like to thank the Commission on Higher Education, the Thailand Research Fund, the Thaksin University, and the Graduate School of Chiang Mai University, Thailand for their financial support.

\section{References}

[1] N. Shahzad and H. Zegeye, "Strong convergence of an implicit iteration process for a finite family of generalized asymptotically quasi-nonexpansive maps," Applied Mathematics and Computation, vol. 189, no. 2, pp. 1058-1065, 2007.

[2] R. Bruck, T. Kuczumow, and S. Reich, "Convergence of iterates of asymptotically nonexpansive mappings in Banach spaces with the uniform Opial property," Colloquium Mathematicum, vol. 65, no. 2, pp. 169-179, 1993.

[3] L. Qihou, "Iteration sequences for asymptotically quasi-nonexpansive mapping with an error member of uniform convex Banach space," Journal of Mathematical Analysis and Applications, vol. 266, no. 2, pp. 468-471, 2002.

[4] H. F. Senter and W. G. Dotson Jr., "Approximating fixed points of nonexpansive mappings," Proceedings of the American Mathematical Society, vol. 44, no. 2, pp. 375-380, 1974.

[5] H. Fukhar-ud-din and S. H. Khan, "Convergence of iterates with errors of asymptotically quasinonexpansive mappings and applications," Journal of Mathematical Analysis and Applications, vol. 328, no. 2, pp. 821-829, 2007.

[6] A. R. Khan, A.-A. Domlo, and H. Fukhar-ud-din, "Common fixed points Noor iteration for a finite family of asymptotically quasi-nonexpansive mappings in Banach spaces," Journal of Mathematical Analysis and Applications, vol. 341, no. 1, pp. 1-11, 2008.

[7] S. Plubtieng and R. Wangkeeree, "Strong convergence theorems for multi-step Noor iterations with errors in Banach spaces," Journal of Mathematical Analysis and Applications, vol. 321, no. 1, pp. 10-23, 2006.

[8] L. Qihou, "Iterative sequences for asymptotically quasi-nonexpansive mappings with error member," Journal of Mathematical Analysis and Applications, vol. 259, no. 1, pp. 18-24, 2001.

[9] L. Qihou, "Iterative sequences for asymptotically quasi-nonexpansive mappings," Journal of Mathematical Analysis and Applications, vol. 259, no. 1, pp. 1-7, 2001.

[10] N. Shahzad and A. Udomene, "Approximating common fixed points of two asymptotically quasinonexpansive mappings in Banach spaces," Fixed Point Theory and Applications, vol. 2006, Article ID 18909, 10 pages, 2006.

[11] Z. Sun, "Strong convergence of an implicit iteration process for a finite family of asymptotically quasinonexpansive mappings," Journal of Mathematical Analysis and Applications, vol. 286, no. 1, pp. 351-358, 2003.

[12] B. Xu and M. A. Noor, "Fixed-point iterations for asymptotically nonexpansive mappings in Banach spaces," Journal of Mathematical Analysis and Applications, vol. 267, no. 2, pp. 444-453, 2002.

[13] N. Petrot, "Modified Noor iterative process by non-Lipschitzian mappings for nonlinear equations in Banach spaces," Journal of Mathematical Analysis and Applications. In press.

[14] S. Suantai, "Weak and strong convergence criteria of Noor iterations for asymptotically nonexpansive mappings," Journal of Mathematical Analysis and Applications, vol. 311, no. 2, pp. 506-517, 2005.

[15] A. Bnouhachem, M. A. Noor, and Th. M. Rassias, "Three-steps iterative algorithms for mixed variational inequalities," Applied Mathematics and Computation, vol. 183, no. 1, pp. 436-446, 2006.

[16] S. H. Khan and W. Takahashi, "Approximating common fixed points of two asymptotically nonexpansive mappings," Scientiae Mathematicae Japonicae, vol. 53, no. 1, pp. 143-148, 2001.

[17] J. U. Jeong and S. H. Kim, "Weak and strong convergence of the Ishikawa iteration process with errors for two asymptotically nonexpansive mappings," Applied Mathematics and Computation, vol. 181, no. 2, pp. 1394-1401, 2006.

[18] S. Plubtieng, R. Wangkeeree, and R. Punpaeng, "On the convergence of modified Noor iterations with errors for asymptotically nonexpansive mappings," Journal of Mathematical Analysis and Applications, vol. 322, no. 2, pp. 1018-1029, 2006. 
[19] H. Fukhar-ud-din and A. R. Khan, "Approximating common fixed points of asymptotically nonexpansive maps in uniformly convex Banach spaces," Computers \& Mathematics with Applications, vol. 53, no. 9, pp. 1349-1360, 2007.

[20] S. H. Khan and H. Fukhar-ud-din, "Weak and strong convergence of a scheme with errors for two nonexpansive mappings," Nonlinear Analysis: Theory, Methods E Applications, vol. 61, no. 8, pp. 12951301, 2005.

[21] M. O. Osilike and S. C. Aniagbosor, "Weak and strong convergence theorems for fixed points of asymptotically nonexpansive mappings," Mathematical and Computer Modelling, vol. 32, no. 10, pp. 1181-1191, 2000.

[22] C. E. Chidume and B. Ali, "Weak and strong convergence theorems for finite families of asymptotically nonexpansive mappings in Banach spaces," Journal of Mathematical Analysis and Applications, vol. 330, no. 1, pp. 377-387, 2007. 


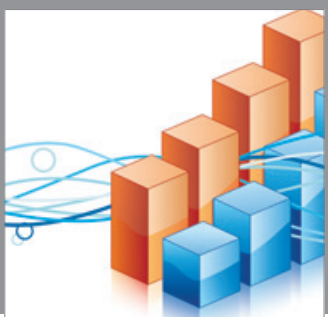

Advances in

Operations Research

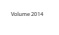

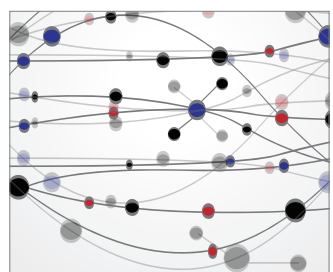

\section{The Scientific} World Journal
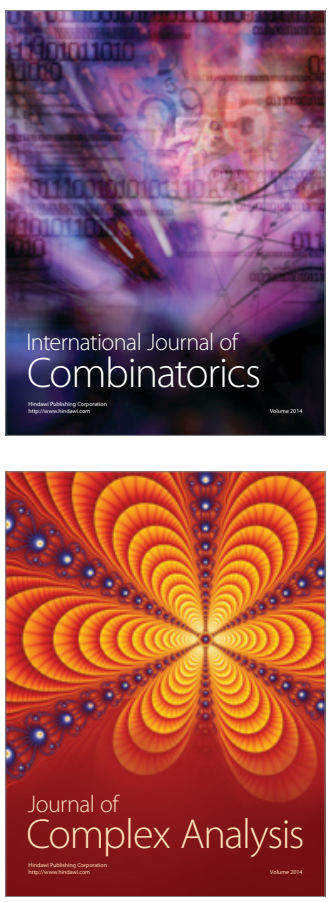

International Journal of

Mathematics and

Mathematical

Sciences
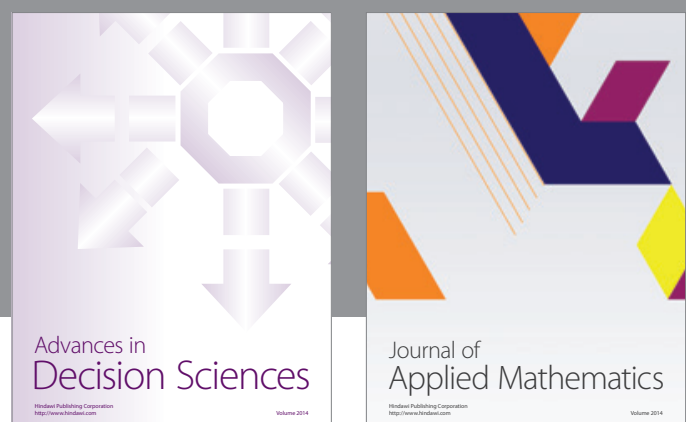

Journal of

Applied Mathematics
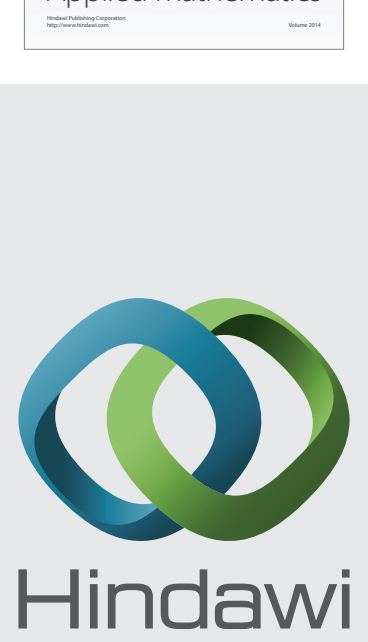

Submit your manuscripts at http://www.hindawi.com
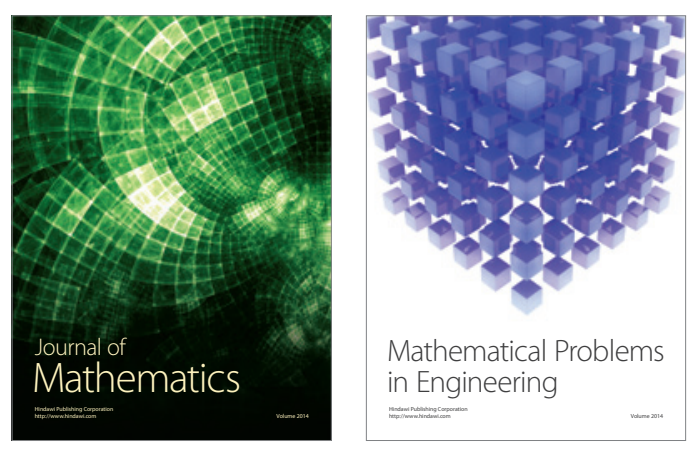

Mathematical Problems in Engineering
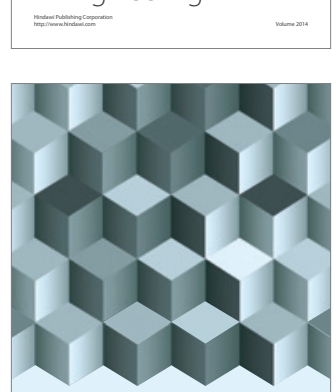

Journal of

Function Spaces
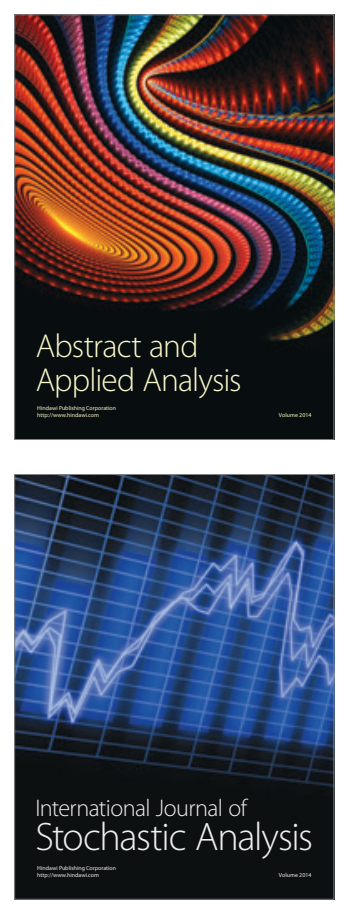

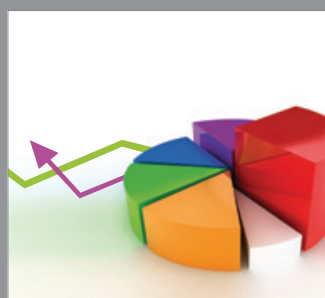

ournal of

Probability and Statistics

Promensencen
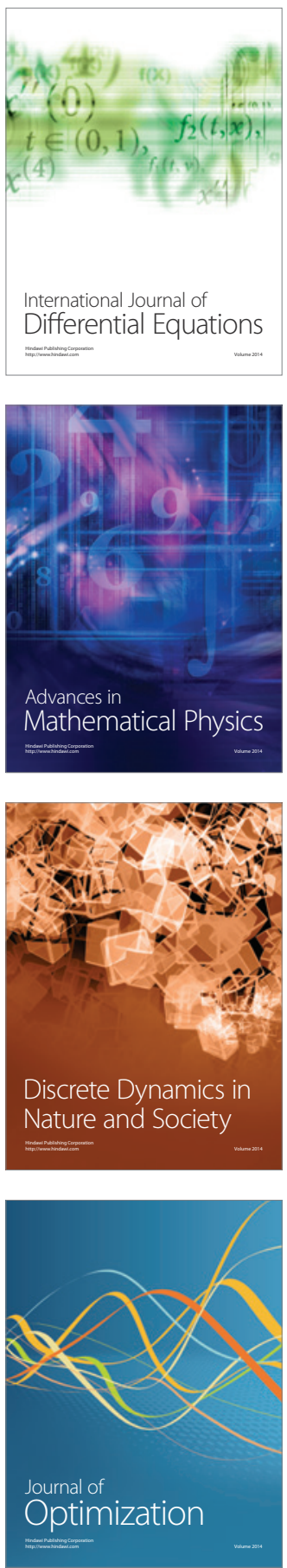